\title{
A FORMAÇÃO DA IDENTIDADE DOCENTE NO CONTEXTO DA INTERIORIZAÇÃO DA EDUCAÇÃO SUPERIOR PÚBLICA EM PERNAMBUCO
}

\author{
THE TRAINING OF TEACHER IDENTITY IN THE CONTEXT \\ OF INTERIORIZATION OF PUBLIC HIGHER \\ EDUCATION IN PERNAMBUCO
}

\section{LA FORMACIÓN DE LA IDENTIDAD DOCENTE EN EL CONTEXTO DE LA INTERIORIZACIÓN DE LA EDUCACIÓN SUPERIOR PÚBLICA EN PERNAMBUCO}

\begin{abstract}
Kênio ERithon Cavalcante Lima ${ }^{1}$
Keoma Tabosa Guimarães Matias ${ }^{2}$

${ }^{1}$ Universidade Federal de Pernambuco (CAV/ UFPE), Vitória de Santo Antão/ PE - Brasil

${ }^{2}$ Secretaria de Educação Municipal de Caruaru (SEDUC), Caruaru/ PE - Brasil
\end{abstract}

Resumo Este estudo tem por foco investigar os impactos da Interiorização da Educação Superior Pública (IESP), colocada como uma realidade em muitas das regiões brasileiras resultado de políticas públicas, na construção da identidade docente e na profissionalização de professores para a Educação Básica nas regiões em que atuam. Por objetivo, analisamos pressupostos didático-metodológicos, qualidade das disciplinas e a importância dos estágios para a formação da identidade e da profissionalização dos futuros professores, na compreensão dos licenciandos. Distribuímos questões discursivas para a Análise de Conteúdo e afirmações para a Escala Likert entre licenciandos do curso de Ciências Biológicas, sujeitos da interiorização que, voluntariamente e na garantia do anonimato, responderam o questionário. Como resultado, observa-se que os licenciandos compreendem a importância do profissional professor das Ciências da Natureza no processo de qualificação da Educação Científica na região, avaliando como significante a formação que possuem. Pontuam positivamente as disciplinas específicas do curso e seus professores quanto à interação que fazem no campo de estágio e com os diversos conteúdos relativos à realidade local. Ratificam o compromisso social da profissão docente, visto como essencial para a construção de sua identidade profissional e da atuação futura em seus municípios de origem.

Palavras-chave: Formação de Professores; Políticas Públicas; Educação Pública; ProFISsionalização Docente; Compromisso Social. 
Abstract The present study is focused to investigate the impacts of the Public Higher Education Internalization (PHEI), applied in many regions of Brazil - as a result of public policies, in the construction of the preceptor's identity and the professionalization of teachers for basic education in their regions. To that we analyze the educational and methodological assumptions, the quality of the disciplines and the importance of the trainee in the construction of the professionalization identity of the forthcoming teachers. The used essay questions are discursive for the content analysis, and affirmative for the Likert scale, applied in the undergraduate student's volunteers of internalized biological sciences course, with the assurance of anonymity. As a result, it is observed that the licensees understand the professional importance of the Natural Science teacher in the Science Education in the educational qualification process in the region, assessing as significant the training experiences that they have. They positively punctuate the specific course subjects and their professors about the interaction that they made in the training field and among the different contents on the local reality. They also ratify the social commitment of the teaching profession, seen as essential to the construction of their professional identity and future performance in their home municipalities.

Keywords: Teacher Education; Public policy; Public education; Teacher ProfessionaliZATION; SOCIAL COMMITMENT.

Resumen Este estudio tiene por foco investigar los impactos de la interiorización de la educación pública superior (IESP), colocada como una realidad en muchas regiones brasileñas - resultado de las políticas públicas, en la construcción de la identidad docente y en la profesionalización de profesores para la Educación Básica en las regiones en que actuan. Por objetivo, analisamos presupuestos didáctico-metodológicos, la calidad de las disciplinas y el valor de las pasantías para la formación de la identidad y de la profesionalización de los futuros profesores. Distribuimos preguntas discursivas para el Análisis de Contenido y afirmaciones para la Escala Likert entre alumnos del curso de Ciencias Biológicas, sujetos de la interiorización que, voluntariamente y en la garantía de anonimato, respondieran al cuestionario. Como resultado, se observa que los alunos entienden la importância del profesional profesor de las ciéncias de la naturaleza en el proceso de calificación de la Educación Científica de la región, evaluando como significativa la formación que poseen. Puntuan positivamente a las disciplinas específicas del curso y a sus profesores en cuanto a la interacción que hacen en el campo de las pasantías y con los diversos contenidos relacionados con la realidad local. Ratifican el compromisso social de la profesión docente, visto como esencial para la construcción de su identidad profesional y la actualización futura en sus municípios de origen.

Palabras clave: Formación de Professores; Políticas Públicas; Educação Pública; Profecionalización Docente; Compromiso Social. 


\section{INTRODUÇÃo}

A história da formação de professores no campo de saberes das Ciências da Natureza no Brasil assume maior destaque em meados do século XX. Como ruptura paradigmática, as décadas de 1950 e 1960 demarcam o desejo e o compromisso de ofertar um ensino de Ciências mais problematizador e com experimentações, o que, na compreensão da época, qualificaria o referido processo de ensino na Educação Básica brasileira (TEIXEIRA, 2013b; LIMA, 2015). De acordo com o referencial, tais pressupostos foram orientados em currículos estadunidenses adotados no Brasil por intermédio de projetos políticos de governo com acordos internacionais, pois havia o claro propósito de formar gerações de cientistas e tecnólogos aptos a desencadearem o desenvolvimento econômico e industrial por meio de avanços científico-tecnológicos no país (REIS, 1968; TEIXEIRA, 1977). Desejava-se, assim, potencializar o desenvolvimento de regiões brasileiras historicamente carentes de tecnologia e de desenvolvimento científico, a exemplo do Norte e Nordeste do Brasil à época, para ampliar o setor industrial como forma de desenvolvimento econômico da população mais carente dessas regiões brasileiras (FURTADO, 1959).

Os projetos políticos, econômicos, de industrialização e científico-tecnológicos nacionais da época, como de costume até os dias atuais, utilizaram a educação para melhor qualificar as pessoas (ROMANELLI, 2002). O propósito de desenvolver a economia e a indústria no Brasil demandou reorganizar os espaços escolares e formar mais professores para capacitar profissionalmente a população produtiva, a qual, historicamente, ainda se fazia desqualificada para o novo contexto desenvolvimentista que passava o país (LIMA, 2015). Como consequência:

(...) no Brasil como no mundo, a segunda metade do século XX foi marcada por uma expansão sem precedentes da demanda e da oferta de cursos de educação superior, ligadas tanto à valorização do saber acadêmico pelo mercado de trabalho quanto ao crescimento da importância da pesquisa acadêmica (BRASIL, 2015, p. 19).

A política para a educação do país se estruturou, à época, com a especificidade de ampliar o conhecimento científico e tecnológico orientados pelos currículos estadunidenses, traduzidos e aplicados no Brasil nos anos de 1960 - Currículo Sputinick, amplamente disseminado pelos Centros de Ensino de Ciências (NARDI, 2005; TEIXEIRA, 2013b; LIMA, 2015). Na compreensão existente entre professores e pesquisadores da época, participantes desse contexto disseminador dos saberes científicos - mediados pelos Currículos Estadunidenses - a implantação desses projetos de governo para o desenvolvimento do país proporcionaria conhecimentos necessários para melhor formar as pessoas cientificamente (LIMA, 2015), de modo a melhor profissionalizá-los para impulsionar a indústria brasileira em regiões historicamente dependentes da agricultura (FURTADO, 1959; REIS, 1968).

No decorrer dessas décadas até os anos iniciais do século XXI, se bem analisarmos, ocorreram significativas mudanças no campo científico educacional; porém, não suficien- 
tes para caracterizar e definir que a educação voltada ao conhecimento das Ciências da Natureza se dispôs para toda a população por conta ainda das muitas fragilidades de muitos dos sistemas educacionais públicos brasileiros (MELLO, 1991; IOSIF, 2007; AKKARIA; SILVA, 2009). Fatidicamente, a docência se perpetua na atualidade como uma classe profissional ainda pouco valorizada social e politicamente, mesmo que se reconheça toda a sua importância para a engrenagem do desenvolvimento científico e tecnológico de qualquer país (FÁVARO; TUMOLO, 2016).

Como realidade, as políticas e projetos atuais voltados para a formação superior e as condições complementares à profissionalização docente não avançaram o necessário para se pensar a escola e o estudante dentro do processo de educação, de forma que apropriasse o estudante dos saberes científicos em muitas das instituições públicas (GATTI, 2010), habilitando-os a utilizar desses saberes no seu contexto social. Como diagnóstico dessa afirmação, é pertinente balizarmos as conclusões estabelecidas em instrumentos avaliativos como o "Programme for International Student Assessment" (PISA) e o Índice de Desenvolvimento da Educação Básica (IDEB) (INEP, 2017), os quais fazem, há muito tempo, descrições das fragilidades dos estudantes brasileiros em aplicar os conhecimentos científicos trabalhados em nossas escolas diante de situações reais em seus contextos sociais (IOSIF, 2007).

Em outro recorte de nossas análises, como diagnóstico, no decorrer da história mais recente da educação pelo Brasil, com marco temporal de meados do século XX ao início do século XXI, ocorreu uma concentração de Instituições de Educação Superior Pública nas capitais e nos grandes centros urbanos do país, com um quantitativo insignificante de vagas ofertadas para atender à população mais carente, considerando o quantitativo de ofertas para a demanda da população escolarizada brasileira (ROMANELLI, 2002). Como consequência, por muito tempo os cursos e as vagas por eles ofertadas inviabilizavam o ingresso de muitos dos estudantes provenientes da Educação Básica pública de pequenos municípios distantes dos locais em que se situavam as Universidades Federais. Pesavam sobre esses estudantes, oriundos da rede pública de ensino, a fragilidade da Educação Básica que lhes era ofertada. Educação essa ainda aquém para competir, de forma igualitária, por vagas nas Universidades Públicas Federais por meio dos processos avaliativos - antigo Vestibular e o atual Exame Nacional do Ensino Médio (ENEM) - quando comparados a estudantes provenientes da rede privada (IOSIF, 2007).

Outro fator determinante sempre esteve na renda familiar, sendo esta balizadora em garantir ou não a permanência do estudante graduando, oriundo das cidades de pequeno porte do interior dos Estados, para se manterem nos grandes centros urbanos - locais em que se concentravam os Campi Universitários - para a manutenção desse durante o período de escolarização/graduação (BRASIL, 2015). A realidade então expressa até pouco tempo não se fazia favorável para muitos egressos da Educação Básica pública de regiões mais carentes economicamente e distantes das capitais e dos grandes centros urbanos pelo Brasil, os quais já possuíam Universidades Federais (LIMA, 2015).

De alguma forma, os sistemas de ensino negligenciaram, tanto na Educação Básica como na Superior, as metas e os parâmetros educacionais estabelecidos legalmente na 
Constituição Brasileira e na Lei de Diretrizes e Bases de 1996 (em vigor) quando não criaram, no decorrer dessas últimas décadas, as condições necessárias para o efetivo exercício da docência de muitos dos nossos professores. Por consequência, os professores ainda sentem dificuldades em disseminar com a qualidade desejada os saberes construídos no percurso formativo, o que diminui a oportunidade dos seus discentes em se apropriarem desses mesmos saberes para se profissionalizarem e se apropriarem dos conhecimentos necessários à vida em sociedade, como meio de maior participação social e qualidade de vida.

Dentro de um novo cenário, no referente à formação de professores e de outros profissionais pelo Brasil, as políticas públicas iniciadas no século XXI no Brasil instituíram a Interiorização da Educação Superior Pública (IESP) como cumprimento do Plano Nacional de Educação (PNE) 2001 a 2010 do Governo Federal (BRASIL, 2001). Nesse contexto, se ampliaram as perspectivas para um aumento no quantitativo de profissionais com formação superior com a expansão da Educação Superior Pública em regiões brasileiras historicamente fragilizadas, carentes de pessoas mais qualificadas em muitas das áreas de conhecimento essenciais para o maior desenvolvimento regional. Entre os diversos objetivos das políticas de expansão dessa Educação Superior, o que ratifica observações anteriores, o PNE define "estabelecer uma política de expansão que diminua as desigualdades de oferta existentes entre as diferentes regiões do País" (BRASIL, 2001, p. 37), a qual se destinou a ampliar o campo de atuação das Universidades Federais em regiões de diversos Estados brasileiros que, por muito tempo, não dispunham dessa educação superior ofertada por instituições públicas (MARQUES; CEPÊDA, 2012; COCCO et al., 2014).

Em uma realidade construída nessa primeira década do século XXI, decorrentes ao Plano Nacional de Educação (BRASIL, 2001), ocorrem mudanças e mais oportunidades aos estudantes de classes sociais mais desfavoráveis. Dentro do projeto de expansão do governo federal - Interiorização da Educação Superior Pública - constata-se que o Nordeste ampliou em 94\% o número de matrículas na Educação Superior em instituições federais ao serem criadas novas universidades públicas e por ampliarem outras já existentes. Com a implantação de novos Campi e de cursos em cidades pelo interior dos Estados brasileiros, mais afastados das capitais e de outros grandes centros econômicos que já possuíam Universidades Federais (BRASIL, 2015), surgem novas oportunidades para se ampliar a formação de professores que atuarão, futuramente, na Educação Básica de suas regiões.

Além da expansão física e de pessoas - novos Campi, novos cursos e contratação de professores e técnicos - instituíram-se também programas com cotas para oportunizar os graduandos menos favorecidos, no referente à renda familiar, a concluírem seus cursos (BRASIL, 2015). Essa é uma realidade vivida por muitos licenciandos de baixa renda familiar, sendo um incentivo e a melhor possibilidade de concluírem o curso, cuja profissão futura, ainda que se faça como uma carreira pouco cogitada entre os egressos da Educação Básica, é uma profissão indispensável em qualquer sociedade na atualidade. Por certo, os licenciandos assistidos por meio da Assistência Estudantil e da Bolsa Permanência obtêm esse apoio financeiro para viabilizar a permanência durante o curso, dando-lhes maiores condições de concluí-lo (BRASIL, 2015). 
Por desafio, frente a muitos outros impasses - econômicos, políticos e sociais, o que não é restrito a regiões tradicionalmente carentes como o Norte e Nordeste brasileiros (VENCO; RIGOLON, 2014), a construção da identidade docente ainda perpassa diversos obstáculos, muitos desses por se entender a docência como um sacerdócio e/ou por se compreender de que ser professor decorre da incapacidade do sujeito de ser outro tipo de profissional mais sucedido e reconhecido economicamente e profissionalmente em nossa sociedade (GATTI, 2010). Nesse contexto historicamente construído, a baixa valorização desse profissional professor põe em dúvidas o desejo de muitos jovens - que reconhecem a importância do ser professor - em se profissionalizarem na docência (VENCO; RIGOLON, 2014).

Na docência, o professor do campo das Ciências da Natureza - como profissional legitimamente constituído - faz-se constantemente desafiado a transpor o conhecimento científico dos grandes laboratórios para o entendimento e aplicação de seus estudantes, com novas propostas metodológicas, diversificando recursos e estratégias a um eficiente ensino e aprendizado dos conhecimentos científicos (MUNFORD; LIMA, 2007; FAGUNDES, 2016). Assim, na construção de uma identidade profissional docente, diante de suas demandas - reconhecida e impetrada pelo Estado, na necessidade de se ver profissional diante da sociedade - o professor se constrói e deve ser reconhecido como um trabalhador que possui uma formação específica e atribuições definidas socialmente (WEBER, 2003). A docência dá ao professor o status de profissional por fazê-lo assumir responsabilidades e executar atividades que lhes foram confiadas, compreendendo que...

...é possível admitir que a questão da profissionalização, entendida como processo que transforma uma atividade desenvolvida no mundo do trabalho mediante a circunscrição de um domínio de conhecimentos e competências específicos, como processo que, calcado nas características de profissões estabelecidas (as profissões liberais), nomeia, classifica uma ocupação como profissão, associando-lhe imagens, representações, expectativas historicamente definidas, ou como processo de reconhecimento social de uma atividade ou ocupação (WEBER, 2003, p. 1.127).

Sendo assim, no compromisso de exercer suas funções profissionais, "a profissionalização da docência compõe-se de três ingredientes fundamentais, mas não suficientes: de saber, de saber-fazer e de saber-ser, apresentados na forma de saberes, de conhecimentos ou de competências" (PUENTES; AQUINO; QUILLICI NETO, 2009, p. 182). Portanto, a profissão docente, entendida como prática social, decorre de um processo de construção do sujeito historicamente situado (PIMENTA, 1997). É desse sujeito professor que se espera o domínio de conhecimentos dentro da especificidade de sua área de formação e de atuação, como também competências para melhor transpor esses conhecimentos historicamente construídos aos seus estudantes em um exercício constante de reflexão de sua prática docente (PIMENTA, 1997; PUENTES; AQUINO; QUILLICI NETO, 2009). 
Mas os desafios na docência são muitos e desgastantes. No contraponto da importância da profissão, situações diversas desqualificam o desejo de se fazer professor e de continuar na profissão (VENCO; RIGOLON, 2014). Entre muitas, a própria organização dos cursos formadores de professores, a exemplo das Ciências Biológicas, destitui a prática docente ao colocar em sua estrutura curricular do curso conteúdos específicos e os professores ministrantes que não conseguem dialogar teoria e prática com as estratégias e recursos didático-metodológicos necessários para o exercício da docência na Educação Básica.

A própria formação dos nossos professores, desde muito tempo, sustenta-se em disciplinas específicas em detrimento das abordagens contempladas e de responsabilidade das disciplinas reconhecidas como pedagógicas (GATTI, 2010; SOUZA; GUIMARÃES, 2011; VILELA; SELLES; ANDRADE, 2013). Por sua característica, as disciplinas pedagógicas atuam na formação docente para melhor apropriar o professor de informações e destrezas para melhor transpor os conhecimentos historicamente construídos, disseminando-os aos seus estudantes nos momentos de ensino para a aprendizagem (AKKARI; SILVA, 2009; VASCONCELOS; LIMA, 2010; TEIXEIRA, 2013b). No ideário de uma boa educação para a apropriação dos saberes científicos no campo das Ciências da Natureza, no compromisso dos seus professores, o "aprender ciências deveria ser algo tão imprescindível quanto aprender a leitura e a escrita, uma apropriação desejável para todos os seres humanos, a ser estabelecida como um fenômeno de massa" (TEIXEIRA, 2013a, p. 801), dando conta de uma formação cidadã, como compromisso social da educação pública.

Ao pensarmos a formação do licenciando das Ciências Biológicas, devemos ponderar sobre o fato de que o currículo para a construção profissional desse docente ainda desafia o futuro professor a aplicar, de forma dinâmica, muito do que é ensinado na formação, no pretexto de ser futuramente aplicado em sua atuação docente. Por certo, cumprindo o papel social, ao se assumir profissional na docência - atuando com responsabilidade - o professor necessita se colocar como colaborador para a transformação da própria condição social do estudante. É nmecessarioecessário criar as situações que transponham o conhecimento do campo científico de forma pertinente e com significado para a realidade do aprendiz. Cria-se, no envolvimento de sua atuação, espaço para que o outro - o estudante - aproprie-se dos diversos conhecimentos das Ciências da Natureza na perspectiva de também transformar sua condição social.

Muitos projetos e programas de governo buscam, ainda mais, definir o processo de ensino na perspectiva de formar as novas gerações dentro de um pressuposto que atenda, com qualidade, a toda a população que, por direito, deveria ter acesso a uma educação pública de qualidade (AKKARIA; SILVA, 2009). Em mais recente perspectiva de Educação aplicada às Ciências da Natureza, coloca-se como desafio o ensino dessa área de conhecimento nos pressupostos da Alfabetização Científica para um ensino das Ciências mais propositivo, contextualizado, problematizador e investigativo, aplicável às expectativas de seus estudantes, enculturando-os com o conhecimento científico então ensinado na escola (CACHAPUZ et al., 2005; CARVALHO, 2007; TEIXEIRA, 2013a; FAGUNDES, 2016). 
Tal proposta assume importância e relevância como projeto de educação científica na perspectiva de que...

...o ensino de ciências concebido à luz de objetivos educacionais mais amplos
que o aprendizado de ciências per si (conhecimentos e procedimentos), assumi-
do como parte da alfabetização, implica práticas pedagógicas que, a um só tem-
po, envolvem e desenvolvem: atividade intelectual, pensar crítico e autônomo,
mobilização consciente e intencional de recursos cognitivos e metacognitivos
(TEIXEIRA, 2013a, p. 806).

Muitos professores ainda possuem receio em trabalhar recursos e estratégias diferentes e atualizadas das que lhes foram ofertadas em sua formação superior (VASCONCELOS; LIMA, 2010). Acresce a tal receio a própria defasagem conceitual científica e metodológica que possuem por não haver constantemente, como direito profissional, as oportunidades de uma formação continuada adequadamente construída (PIMENTA, 1997; DASSOLER; LIMA, 2012), recaindo sobre esses profissionais as responsabilidades pela fragilidade da educação no país, e subsequente fracasso de seus resultados (IOSIF, 2007; INEP, 2017). Nesse contexto e para esta pesquisa, damos destaque à formação de futuros professores que, em condições de investir em educação no contexto das Ciências da Natureza, podem assumir, depois de profissionalizados na docência, o desafio de impulsionar a qualidade da Educação Básica em seus municípios de origem.

Em uma proposta de pesquisa de cunho mais qualitativo para o entendimento da construção da identidade docente, questionamos: como a instituição formadora, no contexto da Interiorização da Educação Superior Pública, colabora com a construção da identidade docente de licenciandos em Ciências Biológicas diante da realidade da Educação Básica Pública em Pernambuco? Para melhor se conhecer sobre a formação e perspectivas de atuação dos futuros professores de Ciências e Biologia, acrescido dos percursos para a profissionalização docente desses no contexto das políticas públicas da Interiorização da Educação Superior Pública em Pernambuco, traçamos os seguintes objetivos: 1. Avaliar o quanto o contexto da Interiorização da Educação Superior Pública colabora com a formação profissional e a perspectiva futura de atuação docente dos licenciandos em seus municípios de origem; 2. Identificar pressupostos didático-metodológicos trabalhados no curso de formação dos licenciandos que colaboram para o futuro ensino das Ciências da Natureza desses na realidade da Educação Básica pública de sua região; 3. Descrever como o curso, suas disciplinas e o campo de estágio colaboram com a construção da identidade docente dos licenciandos em Ciências Biológicas no contexto da Interiorização da Educação Superior Pública em Pernambuco.

\section{Metodologia}

Este estudo é o resultado de desdobramentos de um projeto maior iniciado em 2016, o qual busca entender a relação da Interiorização da Educação Superior Pública (IESP) com 
a formação de licenciandos, graduandos dos cursos resultantes da expansão dessa Educação Superior que acontece no Centro Acadêmico de Vitória da Universidade Federal de Pernambuco (CAV-UFPE), e as perspectivas de atuação profissional docente futura desses licenciandos nos seus municípios de origem.

O curso aqui estudado é a licenciatura em Ciências Biológicas - uma das licenciaturas existente no referido centro (CAV-UFPE), sendo este curso noturno com duas turmas por ano, cada uma ofertando 45 vagas. O referido centro é oriundo do projeto do Governo Federal de Expansão e Interiorização da Educação Superior Pública das Universidades Federais (BRASIL, 2001; 2015), localizado na área urbana do município de Vitória de Santo Antão - PE, o que o caracteriza como instituição situada no interior do Estado, atendendo a estudantes de diversos municípios das regiões do Agreste, Sertão, Zona da Mata e Litoral pernambucano.

O curso em estudo assume o propósito de formar professores para o ensino de Biologia e de Ciências, na perspectiva de disseminar um ensino das Ciências da Natureza mais problematizador e contextualizado (UFPE, 2012), na perspectiva de uma melhor Educação e apropriação de conhecimentos então defendidos na atualidade (VILELA; SELLES; ANDRADE, 2013; FAGUNDES, 2016). Como desafio, precisa articular teoria e prática à problemática social do estudante, dos saberes específicos com os pedagógicos, a serem aplicados e materializados à realidade e às necessidades de muitos dos municípios de onde os licenciandos são oriundos.

O estudo assume procedimentos técnicos de pesquisa do tipo levantamento (MALHEIROS, 2011), em que foi realizado a aplicação de um questionário a oitenta licenciandos em Ciências Biológicas em processo de conclusão de curso, que cursavam do sexto ao oitavo período do curso de licenciatura em Ciências Biológicas no já citado centro (CAV-UFPE). A participação nesta pesquisa foi voluntária, com a garantia de mantermos o anonimato dos participantes, sendo os mesmos identificados, no decorrer do trabalho, com códigos (L1, L10, Lx...). Obtivemos retorno de 32 questionários, os quais são o quantitativo analisado nesta pesquisa.

O questionário (Apêndice 01) se constituiu de diversas questões discursivas e também de afirmações para a pesquisa de opinião (Escala Likert), a qual é utilizada para avaliar o grau de concordância do pesquisado em referência a temáticas diversas com afirmações e/ ou questionamentos sobre o objeto de estudo (MALHEIROS, 2011). As questões foram referentes aos aspectos de formação dos licenciandos no curso e de suas perspectivas de atuação profissional, considerando a realidade da Interiorização da Educação Superior Pública em Pernambuco.

As questões discursivas foram categorizadas a posteriori para melhor entendermos as concepções dos licenciandos, o que nos possibilitou analisar compreensões e as consequentes justificativas entre os pesquisados, na perspectiva qualitativa com investigação na Análise de Conteúdo (BARDIN, 2011). A construção das categorias a posteriori se deu pela fragmentação das respostas discursivas dos licenciandos e consequente agrupamento dos fragmentos que se apresentaram com sentido semelhante. Para melhor analisarmos e caracterizarmos as concepções mais frequentes entre os licenciandos con- 
sultados, além de destacarmos as categorias com valores percentuais, seguimos com a transcrição de fragmentos de suas respostas para dar maior confiabilidade às categorias então trabalhadas neste estudo.

No referente às questões com afirmativas para a escala de opiniões, disponibilizamos algumas afirmações de forma antagônica e outras complementares entre si para posterior análise nos pressupostos do método de coleta da Escala Likert, avaliando o grau de concordância e/ou discordância dos pesquisados diante das afirmações colocadas na pesquisa. Cada afirmativa se estruturou acompanhada com uma escala de $0 \%$ a $100 \%$, com intervalos de $10 \%$. Como forma de organização dos valores construídos com os intervalos assinalados pelos pesquisados nas afirmações propostas, aplicados na Escala Likert, definiu-se que os valores compreendidos nas escalas de $0 \%$ a 30\% determinariam discordância da afirmativa, de $40 \%$ a $70 \%$ concepções intermediárias entre discordância e concordância da referida afirmativa (sem opinião formada), e o intervalo das escalas $80 \%$ a $100 \%$ concordância com a afirmativa. Procedeu-se também à análise comparativa das afirmações com as respostas discursivas para melhor avaliarmos a percepção dos pesquisados sobre a construção de sua identidade docente e acerca dos desafios da docência.

\section{RESUlTAdOS E DisCUSSÃo}

Os licenciandos que integram nossa amostragem são oriundos de diversos municípios - mais de dez municípios diferentes, muitos circunvizinhos ao município de Vitória de Santo Antão. Consta que um pouco mais de 60\% desses licenciandos fizeram seu Ensino Médio em escolas públicas, sendo conhecedores da realidade e das dificuldades que precarizam o processo de ensino nas redes públicas da região. Esse percentual de egressos da Educação Básica pública pode ser até maior, tendo em vista que restringimos esta pesquisa - por ser nosso foco de investigação - aos últimos períodos do curso, em que não tomamos a evasão e a mudança de curso como situações para modificar a distribuição dos licenciandos.

Dando a devida importância a esse primeiro diagnóstico, temos toda uma política da Interiorização da Educação Superior Pública (IESP) das Universidades Federais alcançando seus objetivos ao oportunizar um maior processo formativo de egressos da Educação Básica pública da região ao ingressarem em cursos de licenciatura nas instituições públicas (BRASIL, 2001; 2015), a exemplo da licenciatura em Ciências Biológicas aqui estudada. Como resultado projetado, Brasil (2001) espera em seus objetivos que os profissionais constituídos nos cursos formadores de professores atuem futuramente em suas regiões, ampliando o quantitativo de docentes no mesmo contexto social em que se deu a expansão da Educação Superior Pública, para melhor qualificação profissional e atuação das pessoas na região, o que dá sentido à política de interiorização aqui investigada. Se essa perspectiva se firmar no decorrer dos anos, ratificando resultados parciais (BRASIL, 2015), a IESP trará um real impacto na vida educacional e profissional não somente desses hoje licenciandos - futuros docentes; mas também nos diversos municípios das regiões a que atenderão profissionalmente, confirmando perspectivas projetadas para as atuações profissionais futuras deles e melhorias no processo educacional da Educação Básica da região. 
São resultados expressivos em análises com olhar quantitativo que Brasil (2015) relata, merecedor de reconhecimento. Entretanto, tudo aqui exaltado corre o risco de ser especulativo se não for bem investigado e discutido também qualitativamente diante do contexto e do projeto então identificados, sendo estes a Interiorização da Educação Superior Pública e a formação de professores, em nosso caso, materializado na licenciatura em Ciências Biológicas pelo CAV-UFPE, constituinte dos primeiros resultados descritos por Brasil (2015). Assim, esse diagnóstico preliminar nos instiga, ainda mais, ao desejo de conhecer por meio desta pesquisa o quanto essa política de Interiorização da Educação Superior Pública vem ampliar o processo formativo de professores na região, como também melhor compreender como esses licenciandos, muitos oriundos da Educação Básica pública da região, vêm construindo sua identidade docente e suas perspectivas de atuarem nos mesmos sistemas de ensino da Educação Básica a que foram formados para qualificar os processos de aprendizagem de seus futuros estudantes.

Em pressupostos do curso de licenciatura instituído no CAV/UFPE, que compartilha com projetos do campo do ensino das Ciências da Natureza, torna-se objetivo do processo formativo e da vindoura atuação docente fundamentar esses futuros egressos da licenciatura com conhecimentos em desígnios aos preceitos do campo da Educação, munidos de habilidades estruturadoras para trabalharem as estratégias de forma investigativa e problematizadora (UFPE, 2012), como defendido para o ensino das Ciências e da Biologia (MUNFORD; LIMA, 2007; SANTOS, 2007; TEIXEIRA, 2013a; FAGUNDES, 2016). Tal fato, tornando-se uma realidade, é coerente acreditar na existência de maior aperfeiçoamento nos processos didático-metodológicos e aprimoramento desses futuros professores, munidos de saberes do campo do ensino das Ciências da Natureza, os quais colaborarão para melhor trabalhar os processos à transposição dos conhecimentos aos seus estudantes.

Como consequência de bons resultados - esperados para muitos dos municípios em que os licenciandos atuarão profissionalmente com as disciplinas de Ciências e de Biologia, com efeito nos sistemas de ensino público municipal e estadual da região - está em disporem de melhorias nos processos de aprendizagem de seus estudantes, colaborando com um dos objetivos da Interiorização da Educação Superior Pública (BRASIL, 2015), o qual deseja maior quantitativo de ingressos nos cursos superiores por disporem de "expressivos números da expansão, que transparecem na implantação de novas universidades, nos novos campus universitários e no aumento no número de matrículas" (BRASIL, 2015, p. 31). Em resultados também esperados, coloca-se a melhoria na qualidade da Educação Básica ao se avaliar que a licenciatura em Ciências Biológicas aqui estudada é uma entre outras licenciaturas de áreas de conhecimentos diferentes criadas com essa interiorização, lotadas em diversas regiões pelo Brasil, como as localizadas no interior do Estado de Pernambuco.

Essas perspectivas de melhoria se dão por confrontarmos, ainda, com a realidade da educação pública de muitos dos municípios de regiões do interior do Estado, as quais se colocam com escolas e sistemas de ensino com baixo Índice de Desenvolvimento da Educação Básica "IDEB" (INEP, 2017). O baixo IDEB representa fragilidades e obstáculos reais para se repensar os meios de formação que busquem a qualidade desejada para a 
educação atual, com apropriação de técnicas e de recursos alternativos que se façam propositivos para o processo de construção de uma educação social, científica e tecnológica de grande parte da população brasileira, com enfoque às pessoas da região circunvizinha ao município sede do curso e aos licenciandos pesquisados. O desafio então é buscar a enculturação das pessoas com o conhecimento científico a ser aplicado em seu contexto social (CARVALHO, 2007) - coerente com a realidade local, colaborando para a formação das pessoas, o que preconiza uma atuação docente futura colaborativa para a apropriação dos saberes educacionais, como desejado nos preceitos da Alfabetização Científica (TEIXEIRA, 2013a). É oportunizar que o conhecimento ensinado não se limite a repetir definições; mas, muito mais, habilite as pessoas a utilizarem desse conhecimento para resolver e/ou minimizar seus problemas e melhor formar opinião sobre os problemas de suas comunidades, de nossa sociedade.

Por certo, em diagnósticos construídos nesta pesquisa, temos que os licenciandos consultados reconhecem os diversos desafios, o que lhes impulsiona a procurar soluções e/ ou ações que minimizem seus problemas, em que buscarão inovar e transformar a própria prática docente que tiveram (Tabela 1). Assumem o compromisso de serem mediadores dos processos de aprendizagem para uma formação crítica e científica de seus estudantes ao trabalharem a realidade local para melhor compreenderem e planejarem ações, distintas, em muitos casos, do que a teoria ensina como ideal e perfeito para o sistema de educação pública do país (Tabela 1). Tal constatação é destaque na fala de L08, ao entender que ser professor é "um desafio. Você aplica todo o conhecimento à realidade escolar, que é completamente diferente da teoria vista no curso de licenciatura".

Tabela 1: O ser professor na Educação Básica do Brasil, considerando a área de formação e a realidade do município do licenciando.

\begin{tabular}{l|l}
\hline Categorias & Concordantes \\
\hline Um desafio a ser superado & $68,8 \%$ \\
Uma necessidade de sempre mediar o conhecimento atual, contribuindo & $34,4 \%$ \\
com a formação crítica e científica do estudante & $31,3 \%$ \\
Uma busca para ser inovador e transformador & $25,0 \%$ \\
Sempre muito trabalho e pouca remuneração & $22,0 \%$ \\
\hline Uma realidade escolar e estudantil que demanda trabalhar diferente da teoria & \\
\hline
\end{tabular}

Essa dicotomia entre os saberes construídos na formação e a real atuação docente nos espaços de ensino demanda responsabilidades ao processo formativo por trabalhar diversos saberes necessários à formação da identidade docente do licenciando (TARDIF, 2000). Exigem-se do professor formador e da instituição formadora entendimentos sobre as reais necessidades dos futuros professores, construindo no contexto formativo competências para os licenciandos interpretarem e aplicarem os diversos saberes, transpondo, com coerência, o conhecimento científico a ser ensinado nas escolas. Conhecimentos esses necessários para a formação de pessoas com maior apropriação de saberes nos pressupostos da Alfabetização Científica (CACHAPUZ et al., 2005; SANTOS, 2007; TEIXEIRA, 2013a) 
para melhor entender os acontecimentos sociais que podem ser explicados e resolvidos com conhecimentos do campo das Ciências da Natureza. Por certo, esses ainda são alguns dos desafios da modernidade, os quais exigem dos estudantes em formação na Educação Básica a capacidade de extrapolar o conhecimento da escola para o campo da realidade ao se colocarem enculturados nesse contexto de saberes das Ciências da Natureza (CARVALHO, 2007; TEIXEIRA, 2013a). Aos seus professores, recai a responsabilidade de dar as condições para que essa aprendizagem se efetue da melhor forma possível.

É na busca de transformar a imagem desgastada que a docência ainda tem diante da sociedade e para muitos outros profissionais docentes - fadigados com a sobrecarga de atividades e baixa remuneração - que se exige constantemente das políticas públicas e da própria sociedade o reconhecimento pelo compromisso social que esta profissão tem (RUIZ, 2003). É por mirar nesse reconhecimento e pela importância social do professor que o curso de formação inicial precisa estar conectado para atualizar seus saberes, inserindo os futuros professores nas diversas discussões e perspectivas de sociedade. Pois, na compreensão dos licenciandos, a formação que lhes é ofertada necessita simular o real, saindo do teórico para garantir o prático, ofertando ao futuro professor a possibilidade de aplicar novas metodologias na perspectiva de um ensino mais contextualizado e problematizador. Precisa melhor discutir a realidade social no contexto de ensino da Educação Básica local para melhor questionar a realidade do estudante, pertinente para as transformações imprescindíveis às relações sociais desses (Tabela 2).

A concepção então apontada é afirmada na fala de (L04), quando o mesmo compreende que a formação do licenciando deve se firmar tanto "em conteúdos específicos quanto em pedagógicos, sempre mostrando como serão aplicados esses saberes na realidade da Educação Básica brasileira". Confirma-se assim que o real significado da formação docente se faz quando essa garante, no processo de formação, a articulação dos saberes específicos de modo a dialogar constantemente com os saberes pedagógicos aplicados, revalidados e avaliados no processo formativo para serem significativos a quem ensina e mais acessível a quem estuda e aprende nesse processo (NUNES, 2001; ALMEIDA; BIAJONE, 2007; MACENHAN; TOZETTO; BRANDT, 2016).

Tabela 2: Perspectiva de formação e de atuação profissional dos licenciandos quanto ao curso e à atuação na Educação Básica pública na região.

\begin{tabular}{l|l}
\hline Categorias & Concordantes \\
\hline Novas metodologias & $40,6 \%$ \\
Refletir sobre a prática docente & $28,1 \%$ \\
Estar preparado para as dificuldades da docência & $21,8 \%$ \\
Ter dedicação à Educação Básica & $21,8 \%$ \\
Dominar os conteúdos da área disciplinar & $18,8 \%$ \\
Trabalhar com a realidade das escolas & $12,5 \%$ \\
Ter responsabilidade social & $6,3 \%$ \\
\hline
\end{tabular}


Toda essa apropriação do conhecimento e das estratégias deve ser exercitada nos momentos dos Estágios Supervisionados, em que estabelecem situações de ensino-aprendizagem construídas na formação docente para os seus estudantes, reconhecendo que é no campo do estágio o local propício para materializar o entendimento do que é ser e se fazer professor e profissional da docência, coerentemente com o que se é esperado da profissão (PIMENTA, 1997; BEGO, et al., 2009; CASTOLDI; POLINARSKI, 2009; VILELA; SELLES; ANDRADE, 2013).

Quanto ao compromisso social (Tabela 3), percebe-se que os licenciandos assumem o desejo de ofertarem melhor apropriação de conhecimento aos seus futuros estudantes, comprometendo-se em dinamizar sua atuação docente para uma formação social e crítica quando mediarem os diversos processos propensos à aprendizagem dos seus futuros estudantes no campo científico, discutido no contexto escolar. Reafirmam, assim, que o compromisso do professor nas diversas áreas de conhecimento não está no repasse de informações apenas; mas está na busca permanente de fazer dos conhecimentos, historicamente construídos, um instrumento a favor do estudante diante dos desafios sociais e profissionais que assumirão como sujeitos sociais. Em relação aos conhecimentos científicos, deseja-se enculturar o estudante, dando-lhe as condições de buscar mais conhecimentos para entender a sua realidade e as suas dificuldades, buscando soluções (CARVALHO, 2007).

Busca-se, como compromisso social dos licenciandos, a transformação na educação local, qualificando-a, ainda mais, para uma futura atuação docente, dando a importância de uma educação para a ciência e à tecnologia vinculada aos pressupostos das Ciências da Natureza nos dias atuais (CACHAPUZ et al., 2005; SANTOS, 2007; TEIXEIRA, 2013a; FAGUNDES, 2016). Firmam, assim, a colaboração para o melhor convívio social das pessoas e ao usufruto do conhecimento por parte delas com qualidade de vida. Prezam em dar significado à docência ao entenderem que o papel social do professor se sustenta em diversos compromissos, entre estes atuar "na construção do processo de humanização" (L21) dos seus estudantes e "formar cidadãos críticos, capazes de se inserirem na sociedade e conseguirem uma educação superior de qualidade, visando uma carreira profissional bem sucedida" (L18), o que apropriaria seus estudantes de saberes para uma cultura científica coerente aos pressupostos da sociedade atual (CARVALHO, 2007; SASSERON, 2015).

Tabela 3: O compromisso social dos licenciandos diante do desafio de atuar na Educação Básica Pública.

\begin{tabular}{l|l}
\hline Categorias & Concordantes \\
\hline Dinamismo na profissão para uma melhor atuação docente & $71,9 \%$ \\
Compromisso com a formação social dos estudantes & $53,1 \%$ \\
Compromisso com a formação crítica dos estudantes & $25,0 \%$ \\
Ser mediador nos processos de aprendizagem & $21,8 \%$ \\
Atender ao máximo um quantitativo de estudantes & $9,4 \%$ \\
\hline
\end{tabular}


Em outra questão, tomando como referencial a citação extraída de Pimenta (1997), os licenciandos consideram que a profissão docente, sustentada em um compromisso de ofertar ensino de qualidade, define responsabilidades para com seus estudantes ao oportunizarem uma formação cidadã. Ratificam (os licenciandos - futuros professores) um compromisso social, colocando-se como mediadores para construírem, junto a seus estudantes, saberes e valores pertinentes a esta vida em sociedade (Tabela 4).

Assim, no referente à formação de uma identidade docente, o que faz do curso uma referência, os licenciandos desejam superar desafios da docência que, de acordo com L06, não se restringem apenas a problemas estruturais; mas ao próprio compromisso do professor pelo "dever de sempre buscar melhores formas de se trabalhar os conteúdos". Superando as dificuldades, existentes em qualquer profissão - uma mais que outras, o propósito de construir uma boa base de conhecimento a ser aplicada ao exercício da docência, e aqui destacamos o científico por se tratar de licenciandos em Ciências Biológicas, reforça ainda mais a importância da profissão e do profissional para o desenvolvimento de qualquer país.

Esse compromisso é destaque em diversos estudos, a exemplo de Pimenta (1997); Gatti (2010) e Dassoler; Lima (2012), já que "sem conhecimentos básicos para interpretação do mundo não há verdadeira condição de formação de valores e de exercício de cidadania" (GATTI, 2010, p. 1.360). Como característica comum, a docência de novos professores tende sempre a imitar procedimentos de ex-professores nesse percurso de construir uma identidade docente (PIMENTA, 1997), na certeza de que é na escola e em seu contexto que acontece a verdadeira formação docente e a construção da identidade profissional do professor (TARDIF, 2000; NUNES, 2001; TARDIF, 2002; ALMEIDA; BIAJONE, 2007; MACENHAN; TOZETTO; BRANDT, 2016). Tal parâmetro enriquece a profissão professor por orientar e oportunizar escolhas que recaem no desejo de replicar ou de aperfeiçoar metodologias dos ex-professores sempre para melhor.

Tabela 4: A atuação prática do professor como compromisso social.

\begin{tabular}{l|l}
\hline Categorias & Concordantes \\
\hline Oportunizar a prática social para a formação de cidadãos & $40,6 \%$ \\
Se ver professor mediador e construtor de valores e saberes & $31,3 \%$ \\
$\begin{array}{l}\text { Estimular o desenvolvimento de habilidades e de pensamento crítico do } \\
\text { estudante }\end{array}$ & $18,8 \%$ \\
Superar desafios no exercício da docência & $18,8 \%$ \\
Construir uma boa base de conhecimento para a prática docente & $12,5 \%$ \\
\hline
\end{tabular}

Ainda nesse contexto de análises, temos que os licenciandos entendem que o professor deve ter a oportunidade e a serenidade de diversificar processos avaliativos para melhor valorizar os conhecimentos e o envolvimento dos estudantes no processo de apropriação dos saberes científicos, o que implica mais oportunidades para o estudante expressar o conhecimento que assimilou. Da mesma forma, os futuros professores necessitam expressar e fazer transparecer o prazer por ensinar como condição de estimular os seus estudantes a 
desenvolverem suas habilidades e pensamentos críticos para então, no conjunto, saberem trabalhar coerentemente o conhecimento então construído para ser aplicado na profissão diante de seus futuros estudantes (Tabela 4).

Nesses pressupostos, destacamos a fala de L26, ao considerar que o papel do professor é se colocar "na posição de um profissional que media essa formação, que deve inspirar a conquista de valores, o desenvolvimento das habilidades e a formação integral dos alunos". Assim, reforçam, ainda mais, a importância do professor e do processo educacional a que ele faz parte para colaborar nas transformações e no desenvolvimento no contexto social das pessoas para o bem comum, com sujeitos munidos de conhecimentos que os habilitam a buscar tais conquistas (BULGRAEN, 2010).

Acresce ao compromisso atribuído à atuação docente desse futuro professor de Ciências e/ou de Biologia o desejo de estimular o desenvolvimento de habilidades e de pensamento crítico do estudante. Pois, a atualidade se faz como desafiadora a qualquer cidadão que, sem conhecimento no campo das Ciências da Natureza e capacidade de aplicá-los em suas relações e nas situações sociais, terá dificuldades em discutir criticamente diversos fenômenos atrelados ao próprio desenvolvimento tecnológico atual e em princípios defendidos e aplicados a uma educação contemporânea nos pressupostos da Alfabetização Científica (CACHAPUZ et al., 2005; SANTOS, 2007; TEIXEIRA, 2013a).

Em uma forma metodológica que estabelecemos nesta pesquisa, buscamos, em uma segunda etapa, ratificar percepções apontadas nas questões discursivas. Para tanto, analisamos diversas afirmações (Tabela 5) em que os pesquisados foram avaliados com sua concordância e/ou discordância, dentro da proposta da Escala Likert (Escala de Opiniões), compreensões também exploradas nas questões discursivas.

Ao analisarmos as considerações dos licenciandos em referência às afirmações sobre a formação que possuem no curso (afirmação 01) e as disciplinas pedagógicas ofertadas (afirmação 06), consideram as disciplinas pedagógicas como importantes para a formação docente que estão construindo. Quanto à estrutura física do ambiente formativo (afirmação 10), os licenciandos avaliam o ambiente como deficitário, principalmente no referente à disponibilidade de acessibilidade - direito estabelecido por leis específicas como princípio que garante a inclusão em qualquer contexto social, não sendo diferente na Educação. Realidade que fragiliza o processo formativo daqueles, acrescido com os espaços de convivência também ainda falhos, sendo algo que depende mais de investimentos governamentais e do replanejamento de suas estruturas. Situações essas que se colocam como formativas, tendo em vista que os licenciandos necessitam, também em sua formação docente, construir um olhar crítico no referente à acessibilidade dos espaços formativos e do direito à inclusão para saber questionar quando o seu espaço de atuação docente também não estiver adequado para atender às necessidades de seus estudantes.

Como destacado por Pimenta (1997), "a profissão do professor, como as demais, emerge em dado contexto e momento histórico, como resposta a necessidades que estão postas pelas sociedades, adquirindo status (sic) de legalidade" (p. 6). Ou seja, a formação do professor, e aqui destacamos a compreensão dos licenciandos quanto ao curso (Tabela 
5), tem que articular e ser propositiva para as demandas da sociedade. Por certo, será esse licenciando, futuro professor com o compromisso social, que necessita preparar seus estudantes na mesma perspectiva de também saber exigir e atender as demandas da sociedade quando atuarem profissionalmente, com conhecimentos também orientados no campo das Ciências da Natureza, pertinente para opinar diante das cobranças futuras a eles colocadas.

Tabela 5: O compromisso social dos licenciandos diante do desafio de atuar na Educação Básica Pública.

\begin{tabular}{|c|c|c|c|c|}
\hline & Afirmações & $\begin{array}{l}\mathbf{0 \%} \text { a } \\
30 \%\end{array}$ & $\begin{array}{l}40 \% \text { a } \\
70 \%\end{array}$ & $\begin{array}{l}80 \% \text { a } \\
100 \%\end{array}$ \\
\hline 01 & $\begin{array}{l}\text { O curso de licenciatura que eu realizo atualmente me } \\
\text { oportuniza uma formação docente mais atenta aos problemas } \\
\text { atuais }\end{array}$ & $0,0 \%$ & $37,5 \%$ & $62,5 \%$ \\
\hline 02 & $\begin{array}{l}\text { O pouco reconhecimento da profissão pela sociedade e } \\
\text { pelas políticas educacionais pesou muito na escolha de ser } \\
\text { professor }\end{array}$ & $34,4 \%$ & $34,4 \%$ & $31,2 \%$ \\
\hline 03 & $\begin{array}{l}\text { Tenho a expectativa de aplicar muitas das estratégias } \\
\text { apreendidas na minha formação no meu exercício docente }\end{array}$ & $9,4 \%$ & $25,0 \%$ & $65,6 \%$ \\
\hline 04 & $\begin{array}{l}\text { Ser professor é a minha oportunidade de ajudar minha cidade } \\
\text { a ter maior propagação dos conhecimentos da minha área }\end{array}$ & $15,6 \%$ & $18,8 \%$ & $65,6 \%$ \\
\hline 05 & $\begin{array}{l}\text { Meu compromisso profissional colaborará com a qualidade } \\
\text { do ensino público nas escolas que eu trabalhar }\end{array}$ & $6,3 \%$ & $31,2 \%$ & $62,5 \%$ \\
\hline 06 & $\begin{array}{l}\text { As disciplinas pedagógicas ofertadas pelo meu curso muito } \\
\text { me auxiliam a construir a minha identidade docente e } \\
\text { profissional }\end{array}$ & $3,2 \%$ & $40,5 \%$ & $56,3 \%$ \\
\hline 07 & $\begin{array}{l}\text { Os Estágios obrigatórios do curso me oportunizam perceber } \\
\text { a realidade com as dificuldades e os desafios de ser professor }\end{array}$ & $0,0 \%$ & $12,5 \%$ & $87,5 \%$ \\
\hline 08 & $\begin{array}{l}\text { A escola em que eu participo com os Estágios é uma escola } \\
\text { que eu gostaria de trabalhar como professor }\end{array}$ & $15,6 \%$ & $37,5 \%$ & $46,9 \%$ \\
\hline 09 & $\begin{array}{l}\text { O curso de licenciatura que faço hoje desconsidera, no } \\
\text { processo de aprendizagem, minhas habilidades e experiência } \\
\text { de vida }\end{array}$ & $59,5 \%$ & $25,0 \%$ & $12,5 \%$ \\
\hline 10 & $\begin{array}{l}\text { Considero a estrutura física do CAV adequada para me } \\
\text { oportunizar uma boa formação profissional }\end{array}$ & $15,6 \%$ & $53,2 \%$ & $28,2 \%$ \\
\hline
\end{tabular}

No compromisso de formação docente, as disciplinas pedagógicas acrescem ao processo formativo, confirmado em categorias de análise anteriores. Como destacado pelos licenciandos consultados (Tabela 5), tais disciplinas se tornam importantes no processo de construção de suas identidades docentes por melhor oportunizarem discussões estratégicas para trabalhar os saberes das disciplinas específicas e o porquê de ensiná-las, confirmando a relevância desse campo de conhecimento para a formação dos professores. Assim, é com as discussões teóricas e a construção dos saberes disciplinares no campo pedagógico, com os procedimentos didático-metodológicos para o ensino das Ciências da Natureza, 
que melhor compreenderemos a importância desse campo de saberes quando dialogamos os conhecimentos das disciplinas específicas do curso, o que não se faz de forma simples e espontânea (BEGO et al., 2009; GATTI, 2010; VILELA; SELLES; ANDRADE, 2013; BEJA; REZENDE, 2014).

Os licenciandos também avaliam que há reconhecimento de suas histórias de vida e de suas particularidades por parte do curso (administração e gestão) e de seus professores ao se preocuparem em explorar as habilidades e experiências dos licenciandos no percurso construtivo de suas identidades profissionais docentes (Tabela 5). Esse envolvimento ajuda o licenciando a se perceber, antes de tudo, como um sujeito social que discute sua realidade e de sua comunidade para colaborar com estratégias de ensino mais condizentes com a realidade em que atuará profissionalmente.

Em outro bloco de afirmações, relativas às afirmativas 03,04 e 05 , observa-se que os licenciandos se colocam aptos e com compromisso social a qualificarem o processo de ensino em suas cidades quando realizarem o exercício da docência (Tabela 5), o que ratifica concepções constatadas nas questões discursivas já analisadas. Mesmo diante das dificuldades impostas por condições estruturais das escolas e por baixo reconhecimento financeiro (PIMENTA, 1997; GATTI, 2010), o que é de conhecimento amplo da sociedade, responsável por desqualificar e desestimular a busca da profissão por muitos jovens, temos, entre os licenciandos consultados, concepções divergentes. Muitos se reconhecem como futuros professores $(31,2 \%)$, certos das dificuldades; outros cursam a licenciatura na perspectiva de outras oportunidades profissionais que não a docência $(34,4 \%)$, o que reafirma o desgaste da imagem que a profissão professor demanda para muitos estudantes (afirmação 02). A esse aspecto podemos avaliar diferentes e importantes situações que possam levar o licenciando a evadir do curso em busca de outros cursos de profissão diferente da docência, como também os egressos da licenciatura quando resolvem não serem professores, ainda que o curso que os graduou os habilite para isso.

Ao analisarmos as últimas duas afirmações (07 e 08 - Tabela 5), referentes aos estágios e ao campo de estágio, observamos que os licenciandos confirmam a importância dessa relação para uma melhor formação profissional (CASTOLDI; POLINARSKI, 2009; VILELA; SELLES; ANDRADE, 2013; BEJA; REZENDE, 2014), na certeza de que a formação não se dá só com teorias; mas sim, na vivência e no confronto das situações didáticas estabelecidas na escola (TARDIF, 2000; 2002; ALMEIDA; BIAJONE, 2007; MIRANDA; BRAÚNA; FERENC, 2015; MACENHAN; TOZETTO; BRANDT, 2016). Nas considerações de Vilela e colaboradores (2013), temos que "a imersão dos licenciandos no espaço escolar permite não apenas que os professores sejam formados em meio a tensões, mas cria a possibilidade de compreender as relações entre essas dimensões" (p. 8), o que faz do estágio e da escola em que este acontece momentos de conflitos e um espaço propício para situações de aprendizagem necessárias à docência, essenciais para essa construção da identidade e profissionalidade docente do licenciando (MIRANDA; BRAÚNA; FERENC, 2015).

Quanto às condições de manutenção no curso e aperfeiçoamento complementar, ratificam a importância do Programa Institucional de Bolsas de Iniciação à Docência (PIBID) 
por esse ter oportunizado a eles momentos de exercício de novas propostas didático-metodológicas e da apropriação da realidade da escola com diferenças e momentos complementares ao que oportunizam com os estágios supervisionados. Tal oportunidade durante a graduação faz da futura atuação docente dos licenciandos na sala de aula menos assustadora por esse momento também ser formativo para construir e aplicar o que o curso se propôs a ensinar, ratificando estudos já destacados para a importância desse programa na formação de professores (BEJA; REZENDE, 2014), não sobrepondo a importância do próprio estágio para a formação docente.

Complementando nosso estudo, buscamos conhecer o quanto o lúdico, aplicado com estratégias e recursos didáticos, orientados na formação dos licenciandos, também colabora com uma atuação docente futura, menos conteudista e teorizada. Entre os entrevistados, mais de $80 \%$ se colocam aptos a diversificarem suas estratégias e recursos, embasados com a ludicidade, atribuindo tais competências ao processo formativo que estão tendo e aos professores formadores, com oportunidade de aplicá-los nos momentos vividos nos estágios. Relatam que os seus professores, com destaque para os das disciplinas pedagógicas e das metodologias de ensino, souberam diversificar seus recursos e estratégias, dando-lhes a oportunidade de aplicar esses saberes no estágio e, por conseguinte, quando forem atuar na docência em seus espaços de atuação profissional.

Pois é no exercício de sua prática docente nos campos de estágio que os licenciandos confirmam realizar trocas de experiências com os professores supervisores e aplicam novas propostas e estratégias de ensino, o que vem colaborar com a construção de sua identidade docente tão necessária, confirmando teorias e diagnósticos de estudos anteriores (CASTOLDI; POLINARSKI, 2009). Assim, para Tardif (2000):

\footnotetext{
(...) a prática profissional nunca é um espaço de aplicação dos conhecimentos universitários. Ela é, na melhor das hipóteses, um processo de filtração que os dilui e os transforma em função das exigências do trabalho; ela é, na pior das hipóteses, um muro contra o qual se vêm jogar e morrer conhecimentos universitários considerados inúteis, sem relação com a realidade do trabalho docente diário nem com os contextos concretos de exercício da função docente (p. 12).
}

Ou seja, a construção da identidade docente, ainda que se inicie com os saberes universitários, tomará seu maior entendimento do que é ser professor no contexto da sala de aula, iniciado ainda no processo formativo com as atividades de estágio e com as trocas de experiências com os professores supervisores. São pressupostos que, de certa forma, auxiliarão o futuro professor a reconstruir, com sua prática docente, meios que minimizem obstáculos ainda impostos à educação pública; mas que não poderão ser a justificativa para atestar o seu fracasso.

Acreditamos que é diante dos obstáculos que aprendemos a superá-los, na certeza de que, na docência, diante de cada desafio, o professor consegue construir soluções comuns à profissão por saberem que é na escola que ressignificamos, a cada dia e diante dos desafios, o próprio significado do que é ser professor. Nessa profissão, mais do que em outras, será 
sobre os licenciandos - futuros docentes das Ciências e da Biologia - que comumente recaem os primeiros compromissos e as futuras cobranças em disseminarem conhecimentos científicos construídos historicamente de forma dinâmica, na perspectiva de materializarem com coerência tais conhecimentos para a aplicabilidade de seus estudantes diante de suas realidades.

\section{CONSIDERaÇões Finais}

A confiança no curso e nos professores formadores, mais as condições estruturais e de auxílios viabilizados dentro do projeto da Interiorização da Educação Superior Pública, colaboram para a boa aceitação dos licenciandos quanto aos desafios futuros da docência em Ciências e Biologia em muitos dos municípios pernambucanos de onde são oriundos, o que pode ser uma realidade também consolidada em muitos outros municípios do Brasil com essa interiorização. Os licenciandos consultados acreditam que a formação que estão tendo estrutura suas habilidades para criarem condições de ensino mais contextualizado, o que os coloca aptos a modificarem, dentro das possibilidades estruturais das escolas e do sistema educacional, a ideia a ser superada de uma educação pública falida e desestruturada para qualificar com conhecimentos e cultura científica (CARVALHO, 2007) as novas gerações.

Os pesquisados reconhecem as dificuldades, mas também acreditam que a educação pública em seus municípios lhes dará condições de disseminarem, com responsabilidade, o conhecimento científico construído no curso, aplicando-o dentro de um compromisso social a que a profissão docente assim os exige. Caso não dispuserem de muitos recursos estruturais (laboratórios) e didáticos (modelos, equipamentos), esses licenciandos acreditam dispor de iniciativas para inovar o que for possível para qualificar o processo de ensino. Assim, a construção da identidade docente dos licenciandos aqui consultados se dá no conjunto de diversos fatores, muitos destes também constatados em estudos de diversos pesquisadores no campo da Educação e do Ensino das Ciências. Chama-nos a atenção para a valorização que os licenciandos atribuem ao curso, correlacionando tanto as disciplinas pedagógicas que, articuladas com as específicas, aplicadas na vivência dos estágios, auxiliam-nos no processo de se verem futuros professores, articulando, com maior propriedade, os saberes das disciplinas específicas.

Identificam-se compromissados com a prática docente ao expressarem o reconhecimento de sua importância como professores, mediando a construção de valores e saberes científicos pertinentes a uma vida profissional qualificada para a formação social de seus futuros estudantes. Mesmo reconhecendo diversos desafios, os licenciandos se veem provocados a aplicarem muitos de seus conhecimentos práticos construídos na formação com o campo de estágio à melhoria de suas comunidades, muitas destas situadas em municípios com dificuldades de aplicarem, com responsabilidade, o conhecimento científico historicamente construído a que o ensino das Ciências da Natureza deseja na atualidade.

Em síntese, com a interiorização da Educação Superior e proximidade com pequenos municípios, a exemplo do Centro Acadêmico de Vitória (CAV-UFPE) - vinculado à Uni- 
versidade Federal de Pernambuco, ampliou-se significativamente a presença de estudantes provenientes da Educação Básica Pública da região no curso de licenciandos em Ciências Biológicas e em outros cursos então ofertados pela instituição (MATIAS et al., 2015; MATIAS; LIMA, 2016). Torna-se uma realidade e uma promissora situação a futura presença desses licenciandos, como já acontece com os egressos desse curso, para uma maior e melhor atuação profissional, o que vem a viabilizar a Educação das Ciências da Natureza na região a que o curso atende, disseminando uma Educação/Alfabetização Científica coerente com o processo formativo (CACHAPUZ et al., 2005; TEIXEIRA, 2013a). Fato é que muito mais ainda necessita ser feito e estudado para qualificar, e não apenas quantificar, os reais impactos da Educação Superior Pública (SPELLER; ROBL; MENEGHEL, 2012), com destaque para a formação de professores nas áreas das Ciências da Natureza e o contexto de análises com a Interiorização.

Tendo em vista a carência de profissionais com formação diferenciada nessa área na região, sabendo discutir conhecimentos e explorar a realidade das pessoas ao trabalhar o conhecimento de modo problematizador, questionador, investigativo e contextualizado, o processo formativo aqui analisado nos faz apontar para perspectivas de melhorias no processo educacional da região, no referente ao ensino das Ciências da Natureza. Criam-se ambientes férteis para melhor transpor os saberes e assim melhor formar as pessoas que se profissionalizam, que confiam nos sistemas de Educação Básica Pública ofertada em muitos dos municípios da região como expectativa de também melhorar suas relações e as condições sociais das pessoas atendidas.

Como questionamentos e indicações para pesquisas futuras, torna-se necessário melhor conhecermos como os egressos se veem profissionalmente, atuando na região, e como os novos licenciandos, recém-ingressados no curso, colocam-se na perspectiva de também atuarem futuramente, tendo professores já graduados nesse contexto da Interiorização da Educação Superior Pública atuando profissionalmente na região.

\section{Agradecimentos e apoio}

Aos licenciandos dos cursos de Licenciatura em Ciências Biológicas e em Educação Física do Centro Acadêmico de Vitória (CAV-UFPE) pela solicitude em participarem voluntariamente desta pesquisa; ao CNPq com a aprovação do projeto no Edital Universal de 2016 do primeiro autor deste artigo; à PROEXC pela concessão de bolsa ao coautor deste artigo.

\section{REFERÊNCIAS}

AKKARIA, A.; SILVA, C. P. A Educação Básica no Brasil: vozes de professores da rede pública e privada. Revista Diálogo Educacional, v. 9, n. 27, p. 379-392, 2009.

ALMEIDA, P. C. A.; BIAJONE, J. Saberes docentes e formação inicial de professores: implicações e desafios para as propostas de formação. Educação e Pesquisa, São Paulo, v. 33, n. 2, p. 281-295, 2007. 
BARDIN, L. Análise de Conteúdo (trad.) RETO, A. L. A. São Paulo: Edições 70, 2011.

BEGO, A. M.; SILVA, C. S.; DINIZ, R. E. S.; OLIVEIRA, L. A. A. Transitando da Teoria para a Prática: análise da experiência didática de licenciandos em química. In: VII ENPEC - Encontro Nacional de Pesquisa em Educação em Ciências, Florianópolis, 2009. Disponível em: posgrad.fae.ufmg.br/posgrad/viienpec. Acesso em: 6 de ago. 2015.

BEJA, A. C.; REZENDE, F. Processos de Construção da Identidade Docente no Discurso de Estudantes da Licenciatura em Química. Revista Eletrónica de Enseñanza de las Ciências, v. 13, n. 2, p. 156-178, 2014.

BRASIL. A democratização e expansão da educação superior no país 2003-2014, 2015. Disponível em: portal.mec.gov.br/...pdf/16762-balanco-social-sesu. Acesso em: 20 out. 2015.

BRASIL. Lei n. 010172 - Plano Nacional de Educação, 2001. Disponível em: portal. mec.gov.br/arquivos/pdf/L10172.pdf. Acesso em: 20 mai. 2016.

BULGRAEN, V. C. O papel do professor e sua mediação nos processos de elaboração do conhecimento. Revista Conteúdo, Capivari, v. 1, n. 4, p. 30-38, 2010.

CACHAPUZ, A.; GIL-PEREZ, D.; CARVAlHO, A. M. P.; PRAIA, J.; VIlCHES, A. A Necessária renovação do ensino das Ciências. São Paulo: Cortez, 2005.

CARVAlHO, A. M. P. Habilidades de Professores Para Promover a Enculturação Científica Contexto \& Educação. Editora Unijuí, ano 22, n. 77, p. 25-49, 2007.

CASTOLDI; R.; POLINARSKI, C. A. Considerações sobre o Estágio Supervisionado por Alunos Licenciandos em Ciências Biológicas. In: VII ENPEC - Encontro Nacional de Pesquisa em Educação em Ciências, Florianópolis, 2009. Disponível em: posgrad.fae. ufmg.br/posgrad/viienpec. Acesso em: 20 jun. 2015.

COCCO, R.; NUNES, G. L.; SANTOS, S. A.; KEMPKA, S. B. Política de Expansão e Interiorização/Regionalização do Ensino público Superior no Brasil: o caso da UFSM/ CESNORS - uma perspectiva a partir do egresso. In: IV Congresso Ibero-Americano de Política e Administração da Educação / VII Congresso Luso Brasileiro de Política e Administração da Educação, Porto, Portugal, 2014. Disponível em: www.anpae.org.br. Acesso em: 20 ago. 2016.

DASSOLER, O. B.; LIMA, D. M. S. A Formação e a Profissionalização Docente: características, ousadia e saberes. In: IX ANPED SUL - Seminário de Pesquisa em Educação da Região Sul, 2012. Disponível em: www.ucs.br/etc/conferencias/anpedsul. Acesso em: 20 jun. 2015. 
FAGUNDES, T. B. Os conceitos de professor pesquisador e professor reflexivo: perspectivas do trabalho docente. Revista Brasileira de Educação, 21, 65, p. 281-298, 2016. Disponível em: www.scielo.br/pdf/rbedu/v21n65/1413-2478-rbedu-21-65-0281.pdf. Acesso em: 5 mar. 2019.

FÁVARO, N. A. L. G.; TUMOLO, P. S. A relação entre Educação e Desenvolvimento Econômico no Capitalismo: elementos para um debate. Educação \& Sociedade, Campinas, v. 37 , n. 135 , p. 557-571, 2016.

FURTADO, C. A Operação Nordeste. Rio de Janeiro: MEC/Instituto Superior de Estudos Brasileiros, 1959.

GATTI, B. Formação de Professores no Brasil: características e problemas. Revista Educação \& Sociedade, v. 31, n. 113, p. 1.355-1.379, 2010.

INEP, PISA e o IDEB - INEP, 2017. Disponível em: inep.gov.br/pisa-e-o-ideb. Acesso em: 10 dez. 2017.

IOSIF, R. M. G. A Qualidade da Educação na Escola Pública e o Comprometimento da Cidadania Global Emancipada: implicações para a situação de pobreza e desigualdade no Brasil. Tese de Doutorado do Programa de Pós-Graduação em Política Social da Universidade de Brasília, 2007, 310s.

LIMA, K. E. C. Discurso de professores e documentos sobre o experimento do CECINE (Centro de Ensino de Ciências do Nordeste) nas décadas de 1960 e 1970. Tese de Doutorado do programa de Pós-Graduação em Educação da UFPE, 2015, 230 s.

MACENHAN, C.; TOZETTO, S. S.; BRANDT, C. F. Formação de professores e prática pedagógica: uma análise sobre a natureza dos saberes docentes. Práxis Educativa, Ponta Grossa, v. 11, n. 2, p. 505-525, 2016. Disponível em: www.revistas2.uepg.br/.../8738/5156. Acesso em: 20 dez. 2017.

MARQUES, A. C. H.; CEPÊDA, V. A. Um Perfil sobre a Expansão do Ensino Superior Recente no Brasil: aspectos democráticos e inclusivos. Revista Perspectivas, v. 42, p. 161-192, 2012.

MATIAS, K. T. M.; LIMA, K. E. C. Os desafios da docência e a importância da formação continuada para recém-graduados ao ensino de Ciências e de Biologia. In: III Congresso Nacional de Educação, Natal - RN, 2016. Disponível em: www.editorarealize.com.br/... /conedu/anais.php. Acesso em: 12 out. 2016.

MATIAS, K. T. M; SANTOS, J. P. J. P.; LIMA, G. H.; LIMA, K. E. C. A interiorização e a construção da identidade docente de Licenciandos em Ciências Biológicas. In: X Encontro 
Nacional de Pesquisa em Educação em Ciências (X ENPEC), Águas de Lindóia-SP, 2015. Disponível em: www.xenpec.com.br/anais2015. Acesso em: 8 out. 2016.

MELLO, G. N. Políticas públicas de educação. Estudos Avançados, v. 5, n. 13, São Paulo, p. 06-47, 1991.

MIRANDA, E. S.; BRAÚNA, R. C. A.; FERENC, A. V. Formação e Atuação Docente: relações e peculiaridades dos campos de saberes. Comunicações, ano 22, n. 1, p. 65-82, 2015.

MUNFORD, D.; LIMA, M. E. C. C. Ensinar ciências por investigação: em quê estamos de acordo? Revista Ensaio: Pesquisa em Educação em Ciências, v. 9, p. 1-20, 2007.

NARDI, R. Memórias da educação em Ciências no Brasil: a pesquisa em ensino de física. Investigações em Ensino de Ciências, v. 10, n. 1, p. 63-101, 2005.

NUNES, C. M. F. Saberes Docentes e Formação de Professores: um breve panorama da pesquisa brasileira. Educação \& Sociedade, ano XXII, n. 74, p. 27-42, 2001.

PIMENTA, S. G. Formação de Professores - saberes da docência e identidade do professor. Revista NUANCES, v. III, p. 05-14, 1997.

PUENTES, R. V.; AQUINO, O. F.; QUILLICI NETO, A. Profissionalização dos professores: conhecimentos, saberes e competências necessários à docência. Educar. Curitiba: Editora UFPR, n. 34, p. 169-184, 2009.

REIS, J. Educação é Investimento. São Paulo: IBRASA, 1968.

ROMANELLI, O. O. História da Educação no Brasil (1930/1973), 27. ed. Petrópolis: VOZES, 2002.

RUIZ, M. J. F. O papel social do professor: uma contribuição da filosofia da educação e do pensamento freireano à formação do professor. Revista Iberoamericana de Educación, n. 33 , p. $55-70,2003$.

SANTOS, W. L. P. Educação científica na perspectiva de letramento como prática social: funções, princípios e desafios. Revista Brasileira de Educação, v. 12 n. 36 set./dez., p. 474-550, 2007.

SASSERON, L. H. Alfabetização Científica, Ensino por Investigação e Argumentação: relações entre ciências da natureza e escola. Revista Ensaio: Pesquisa em Educação em Ciências. Belo Horizonte, v. 17, n. especial, p. 49-67, 2015.

SOUZA; C. A.; GUIMARÃES, Y. A. F. Representações dos Licenciandos sobre seu Curso de Formação Inicial: influências sobre sua identidade profissional em construção. VIII 
ENPEC - Encontro Nacional de Pesquisa em Educação em Ciências, Campinas-SP, 2011. Disponível em: www.nutes.ufrj.br/abrapec/viiienpec/resumos. Acesso em: 20 jun. 2015.

SPELLER, P.; ROBL, F.; MENEGHEL, S. M. Desafios e perspectivas da educação superior brasileira para a próxima década. Brasília: UNESCO, CNE, MEC, 2012, p. 164. Disponível em: unesdoc.unesco.org/images/0021/002189/218964POR. Acesso em: 10 jun. 2015.

TARDIF, M. Saberes docentes e formação profissional. Rio de Janeiro: Vozes, 2002.

TARDIF, M. Saberes profissionais dos professores e conhecimentos universitários Elementos para uma epistemologia da prática profissional dos professores e suas consequências em relação à formação para o magistério. Revista Brasileira de Educação, n. 13, jan./abr., p. 5-24, 2000.

TEIXEIRA, A. Educação e o Mundo Moderno, 2. ed. São Paulo: Cia. Editora Nacional, $1977,245 p$.

TEIXEIRA, F. M. (a) Alfabetização Científica: questões para reflexão. Ciência \& Educação, v. 19, n. 4, p. 795-809, 2013.

TEIXEIRA, F. M. (b) Uma Análise das Implicações Sociais do Ensino de Ciências no Brasil dos anos 1950-1960. Revista Eletrónica de Enseñanza de las Ciencias, v. 12, n. 2, p. 269-286, 2013.

UFPE - Universidade Federal de Pernambuco. Projeto Pedagógico do Curso (PPC) Licenciatura Em Ciências Biológicas - Centro Acadêmico de Vitória (CAV), 2012. Disponível em: www.ufpe.br/cav. Acesso em: 10 dez. 2017.

VASCONCELOS, S. D.; LIMA, K. E. C. O Professor de Biologia em Formação: reflexão com base no perfil socioeconômico e perspectivas de licenciandos de uma universidade pública. Ciência \& Educação, v. 16, n. 2, p. 323-340, 2010.

VENCO, S.; RIGOLON, W. Trabalho Docente e Precariedade: contornos recentes da política educacional paulista. Comunicações, ano 21, n. 2, p. 41-52, jul./dez. 2014.

VILELA, M. L.; SELLES, S. L. E.; ANDRADE, E. P. Vivências Profissionais e Construção da Disciplina Escolar Biologia na Formação Inicial de professores. Revista Educação: Teoria e Prática, v. 23, n. 44, p. 46-62, 2013.

WEBER, S. Profissionalização Docente e Políticas Públicas no Brasil. Revista Educação \& Sociedade, Campinas, v. 24, n. 85, p. 1.125-1.154, 2003. 


\section{DADOS SOBRE OS AUTORES}

\section{Kênio Erithon Cavalcante Lima}

Doutor em Educação pela Universidade Federal de Pernambuco. Pernambuco/PE-Brasil. Professor e Coordenador do Programa de Pós-Graduação do Mestrado Profissional em Ensino de Biologia. Pernambuco/PE-Brasil . Professor no Programa de Pós-Graduação em Educação. Pernambuco/PE-Brasil. Professor na Graduação no Curso de Ciências Biológicas no Centro Acadêmico de Vitória. Pernambuco/PE-Brasil. keclima@ig.com.br

\section{Keoma Tabora Guimarães Matias}

Graduado em Educação Física pela Universidade Federal de Pernambuco. Pernambuco/PE-Brasil. Professor na Educação Básica pela Secretaria de Educação Municipal de Caruaru/-PE- Brasil e na Rede Privada de Ensino. Caruaru/-PE- Brasil. keoma_tabosa@ hotmail.com

Submetido em: 17-3-2019

Aceito em: 14-11-2019 